\title{
AtLAS de TeRRAS IndíGENAS DE ALAGOAS
}

\author{
SILOÉ AMORIMํㅡ EQUIPE AVAL ${ }^{2}$
}

Este encarte fotográfico faz parte do acervo do AVAL - Laboratório Antropologia Visual em Alagoas do Instituto de Ciências Sociais/ICS da Universidade Federal de Alagoas/UFAL e caracteriza pelo levantamento de dados e registro fotográfico para 0 Atlas de Terras Indígenas de Alagoas, projeto desenvolvido entre 2006 e 2007, coordenado pela antropóloga Silvia Martins (ICS/UFAL). A necessidade de publicar o Atlas nos levou a delinear outro plano de trabalho para a revisão e monitoramento do levantamento de dados para a atualização do Atlas de Terras Indígenas em Alagoas, envolvendo os alunos do Curso de Ciências Sociais do ICS/UFAL em parceria com os alunos da Licenciatura Indígena (CLIND) da Universidade Estadual de Alagoas/UNEAL, curso específico destinado à formação em nível superior de professores indígenas vinculados às escolas indígenas em Alagoas e Sergipe. 0 objetivo desse plano de trabalho tinha como base estimular estudantes de ambos os cursos para interagirem entre si sobre questões de pesquisa e também para que desenvolvessem estudos em áreas indígenas. Este último projeto foi uma ação de extensão que rendeu bons resultados: dos sete alunos da UFAL envolvidos nesse plano de trabalho de atualização, quatro concluíram TCC sobre questões indígenas em Alagoas, dos quais dois, seguiram também com projetos para o mestrado em Antropologia sobre etnias indígenas no estado. Os alunos e alunas do CLIND, tiveram a oportunidade de revisar os dados do Atlas das Terras Indígenas em Alagoas entre 2013 e 2016, nesse período coordenado pelo antropólogo Siloé Amorim. Esses alunos também contribuíram para a formulação e problematização dos novos conteúdos que iriam ser agregados aos novos dados do Atlas. De modo que, este encarte reúne fotografias dos primeiros pesquisadores, dos quais vários concluíram também seus trabalhos de graduação, mestrado e doutorado sobre questões indígenas locais. Alguns alunos do CLIND em conjunto, ao revisarem o Atlas de 2007, concluem que: 
"Na nossa revisão para a atualização, vimos dados importantes que precisam ser colocados. Como, por exemplo, dados atualizados das etnias que ressurgiram e que lutam pelo seu reconhecimento e direito a terra como é o caso dos Kalankó, Karuazu, Katokinn, Koiupanká; dos Kanxagós (Pacatuba-SE) e Funkaxós (Índios que tem misturas de Fulni-ô, PE e Kariri - Xocó, AL, que têm a sua etnia histórica misturada com mais sete etnias), informações que precisam de uma etnografia atualizada, já que convivem em uma complexa plurietnicidade, características que compõem as etnias indígenas contemporâneas no nordeste brasileiro que historicamente partilham uma existência em aldeamentos missionários, nos primeiros séculos da colonização com o intuito de segregar-nos. E, atualmente, em Postos e Reservas Indígenas, situação que, apesar da tutela e da insuficiência de terra para um melhor viver, nos permite nos organizar e resistir com nossas especificidades étnicas indígenas. Também percebemos que necessitamos de uma atualização etnográfica na área da educação, saúde e dentro da área social e econômica sobre os povos indígenas que ressurgiram e daqueles que são mais antigos aqui no Estado. Dados esses que poderão ser atualizada a partir de uma pesquisa junto às comunidades sobre a população, educação, saúde, presença ou não de Posto Indígena e a situação das terras indígenas. Outras informações contidas no Atlas permanecerão, pois satisfazem as expectativas sobre os dados históricos das etnias indígenas em Alagoas como são por hora, os dados históricos de cada etnia. Outras informações relacionadas às lideranças e hierarquias construídas no passar do tempo em cada comunidade, podem ser aprofundadas com cada liderança em suas comunidades, considerando que a história situacional indígena, sobretudo em Alagoas, é parcial e fragmentada, pois é feita por pedaços a cada tempo."

Nota: Texto coletivo dos e das alunas da primeira turma do CLIND - Curso de Licenciatura para Professores Indígenas do Programa de Apoio à Formação Superior e Licenciaturas Interculturais Indígenas (PROLIND) (20102014), convidados a participarem da pesquisa de atualização do Atlas de Terras Indígenas de Alagoas (MARTINS, 2007) para publicação no Campus III da Universidade Estadual de Alagoas - Palmeira dos índios, Alagoas, entregue no dia 27 de novembro de 2012. Apoio professores do Cursos de Licenciaturas Interculturais Indígenas - CLIND/UNEAL - Universidade Estadual de Alagoas, Campus III - Palmeira dos Indios, AL.: Iraci Nobre da Silva,José Adelson Lopés Peixoto,Mary Selma Oliveira Ramalho e Maria Margarete de Paiva Silva. 


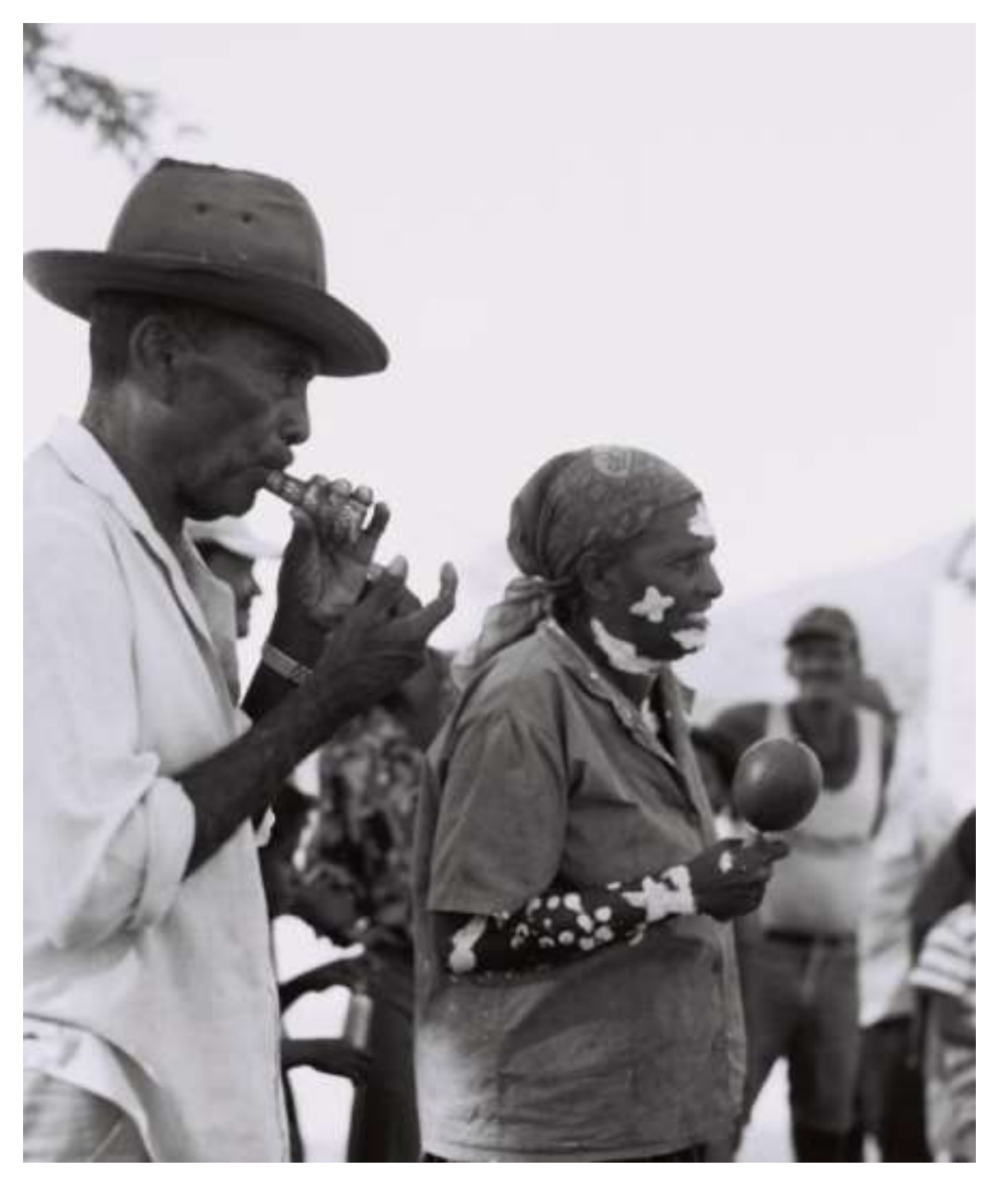

Cacique Genésio Geripacó,
tu. S/d. Foto: Celso Brandão

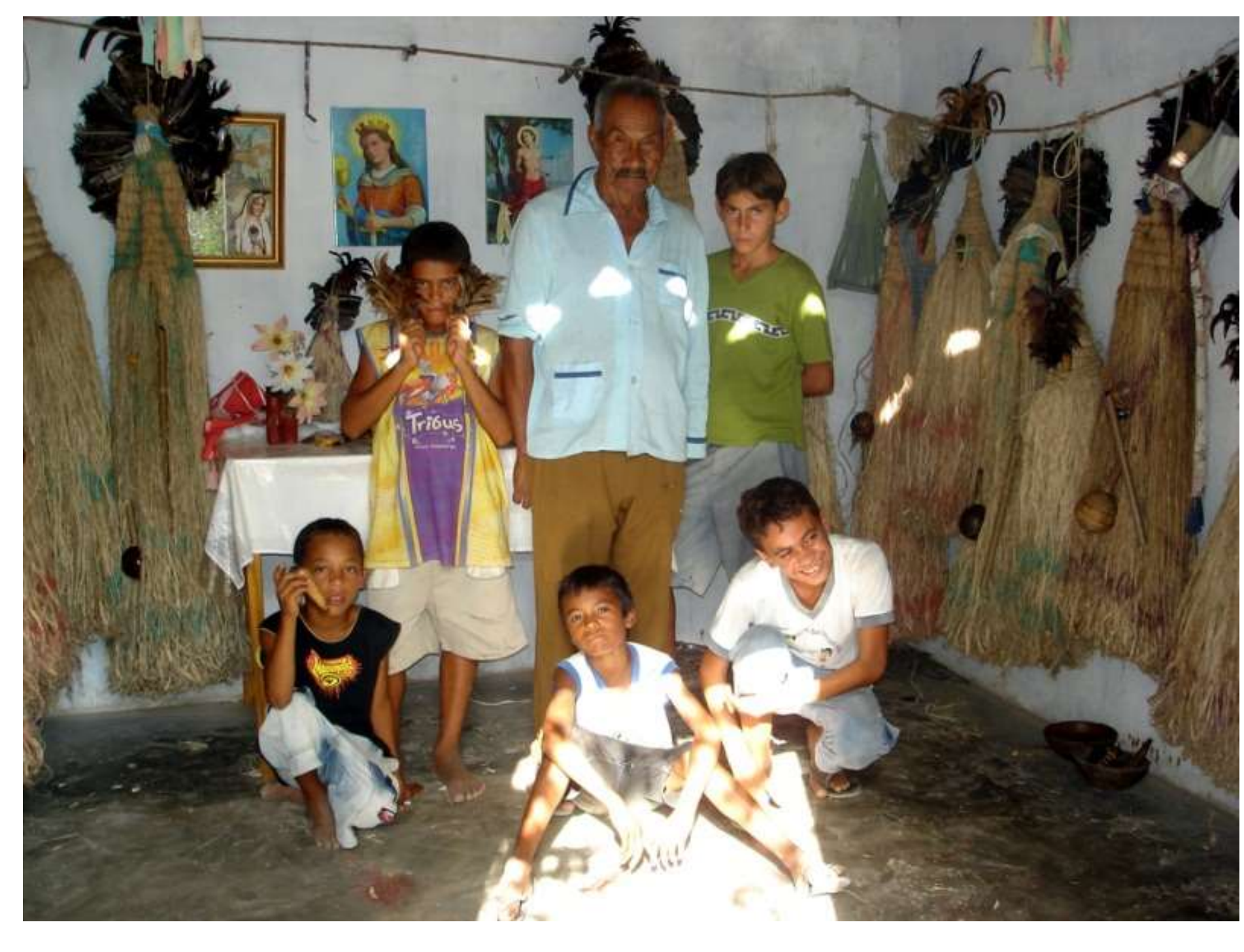

Casa dos Homens, local onde ficam guardados os Praiá, 2006. Foto: Siloé Amorim

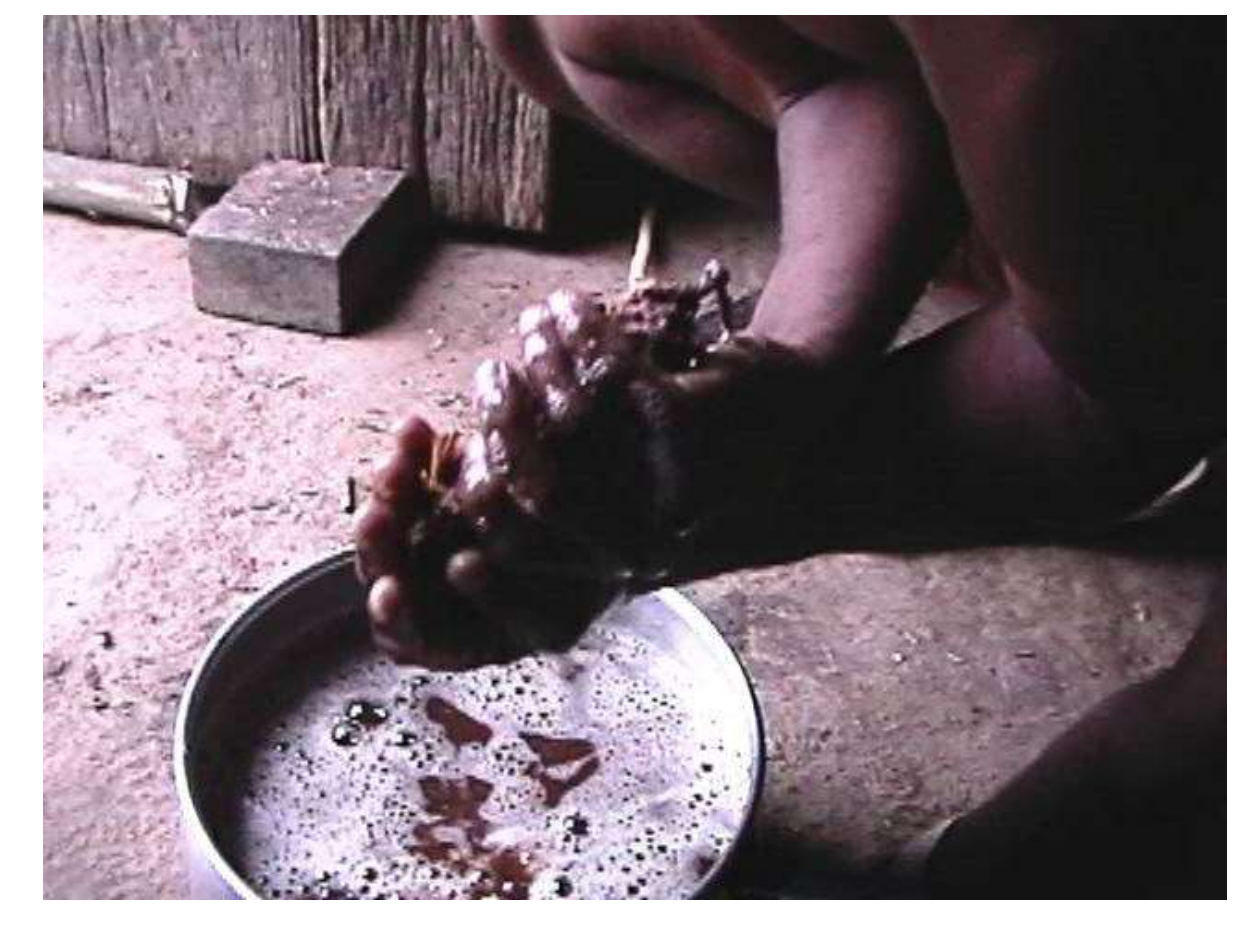
Kennedy Kariri-Xocó fazendo remédio com imburana de cambão, 2002.
Digital still: Silvia Martins 

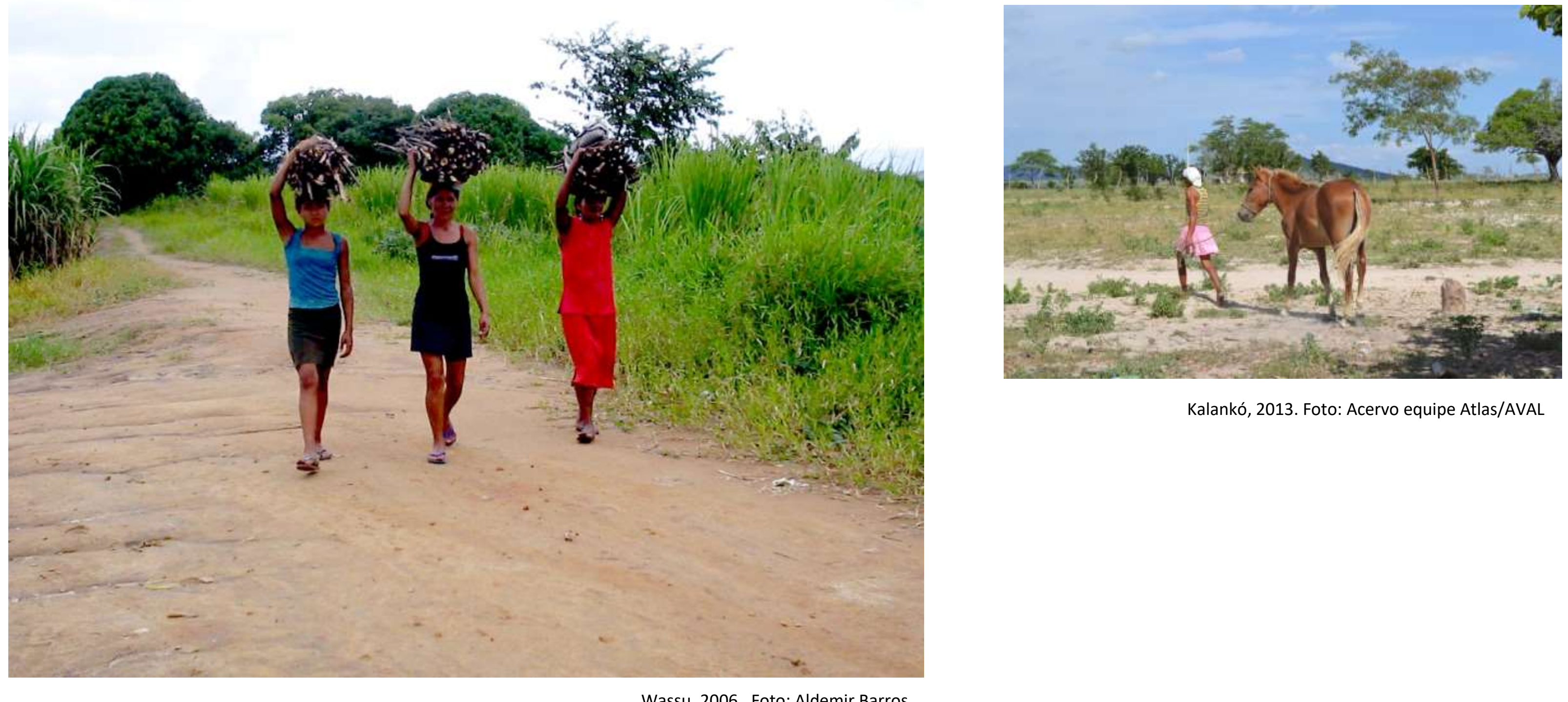

Kalankó, 2013. Foto: Acervo equipe Atlas/AVAL

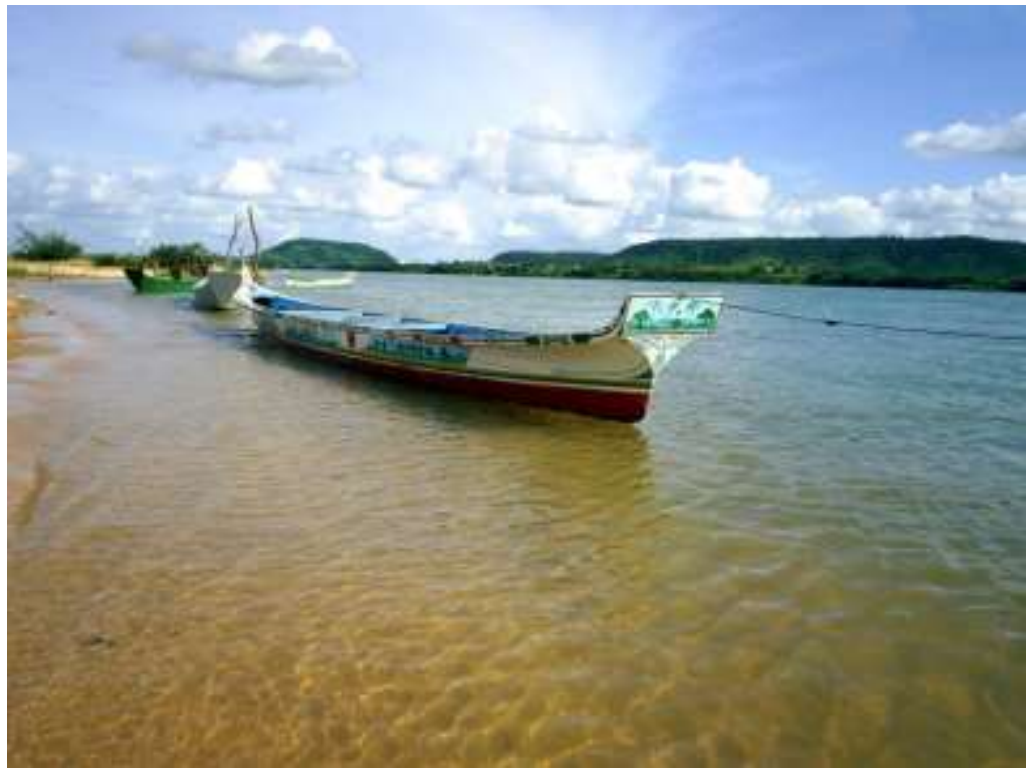




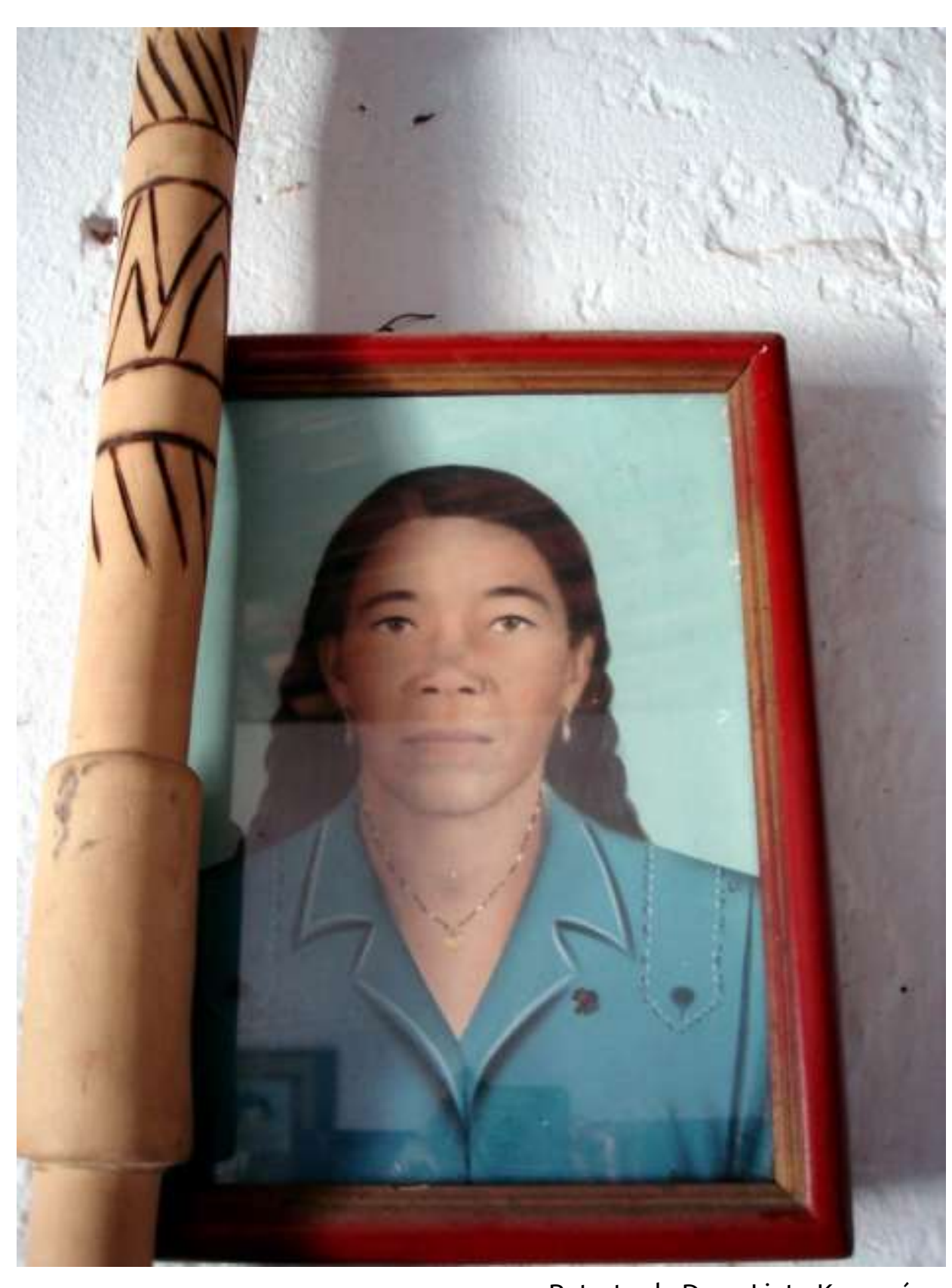

Retrato de Dona Liete Karuazú,
na parede de sua casa, 2006. Foto: Juliana Barreto.



Artefatos arqueológicos - cerâmicas -Urnas funerárias e potes. Acervos sob a
salvaguarda do Museu Xurus - Palmeira dos İndios, AL, 2006.

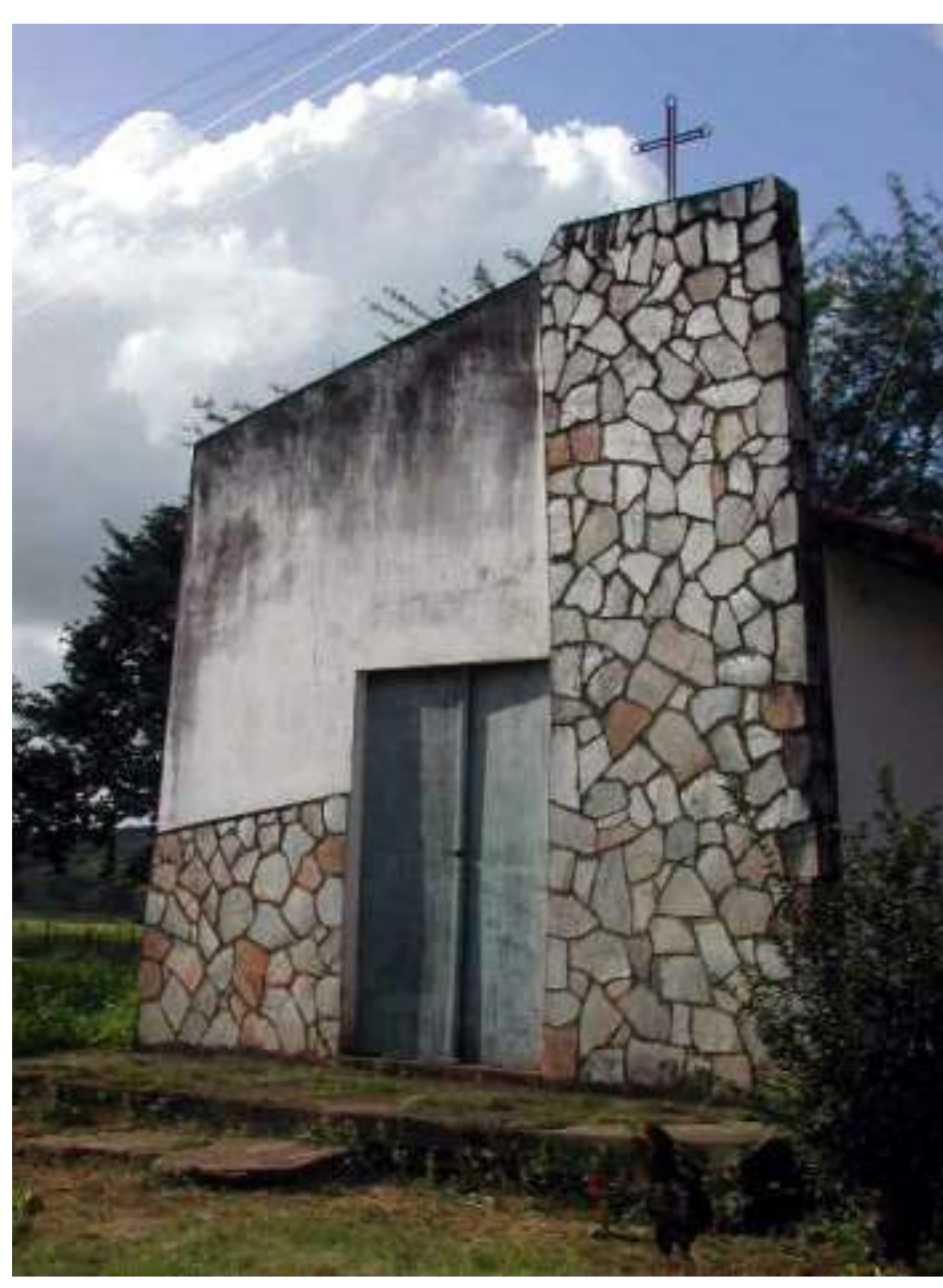

Igrejinha localizada na área
Indígena Aconã, 2006. Foto: Ana Laura Loureiro 


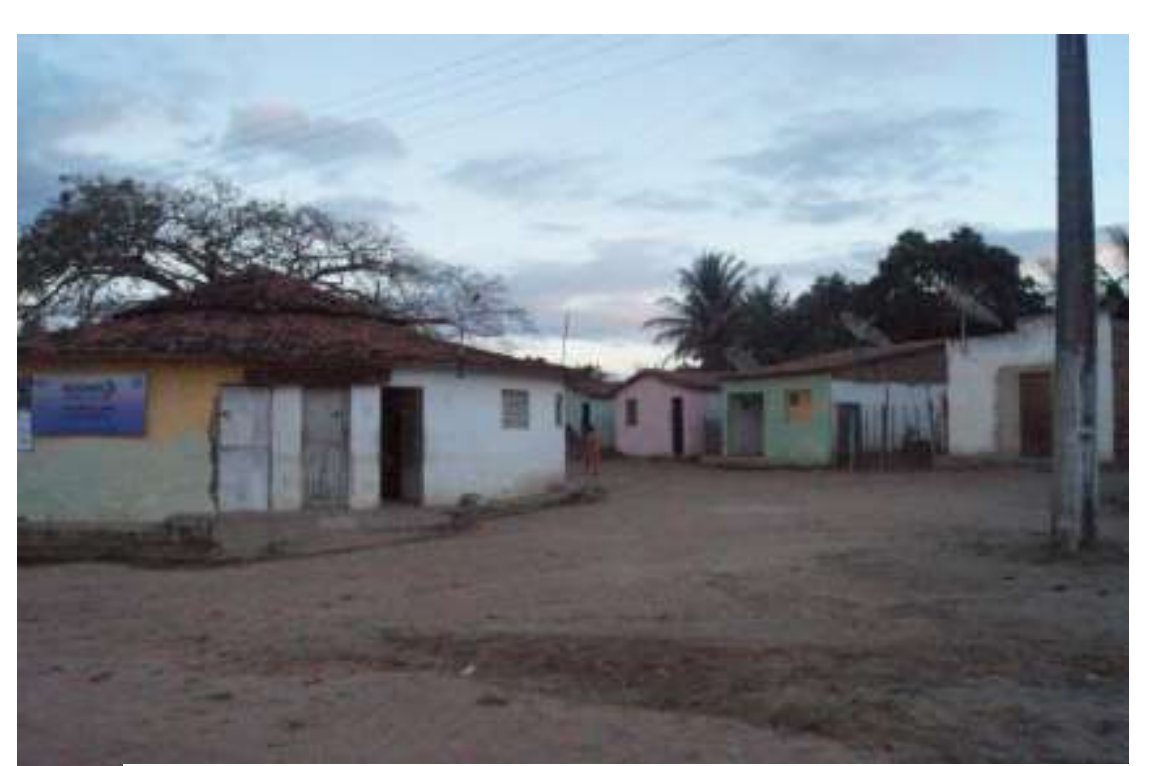

Tingui Botó, 2013. Acervo equipe Atlas/AVAL

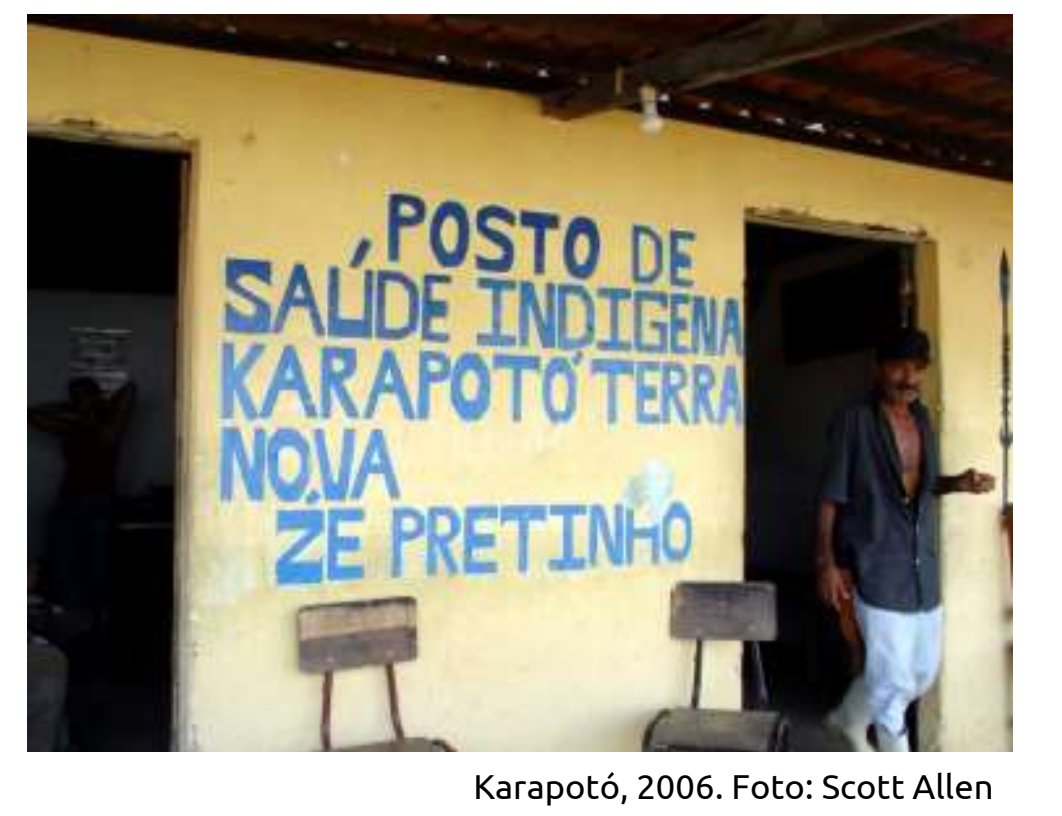

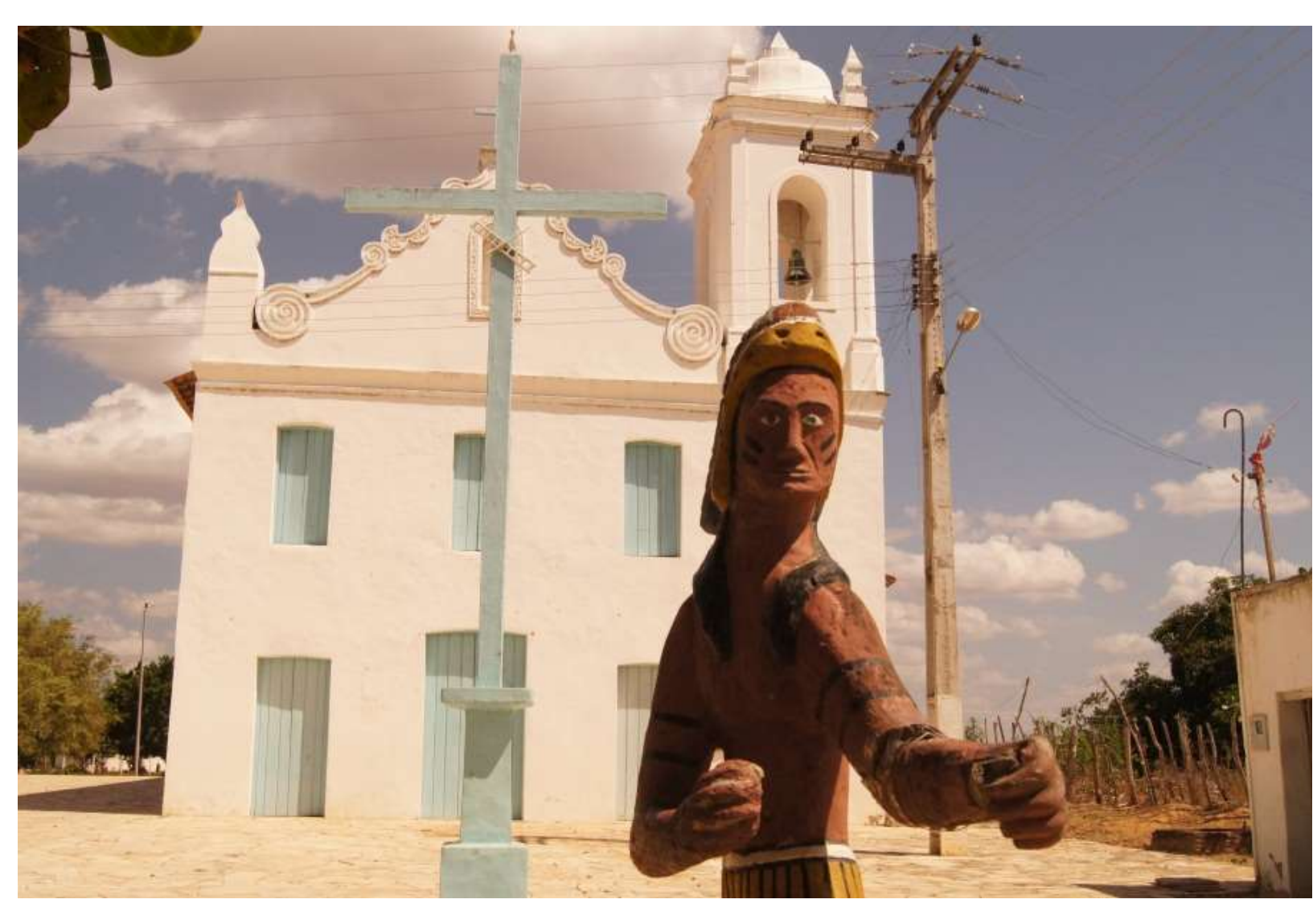

Xocó, llha São Pedro, SE/2013. Acervo equipe Atlas/AVAL

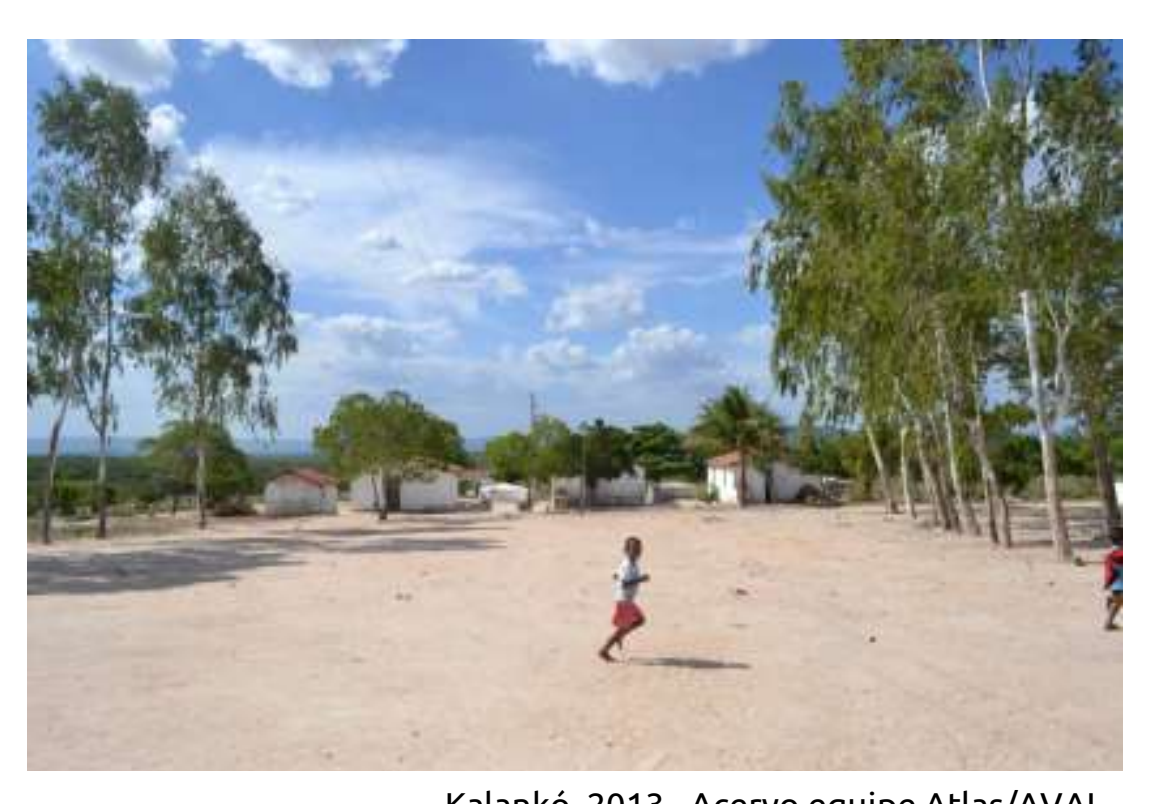

Kalankó, 2013. Acervo equipe Atlas/AVAL

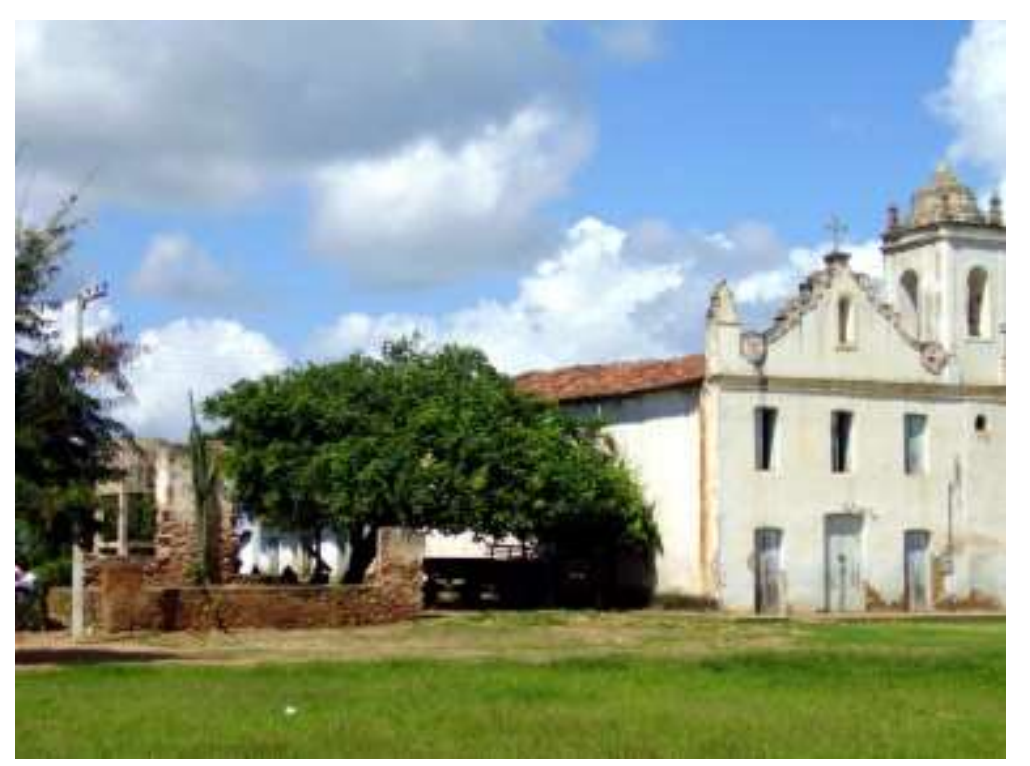

Igreja de São Pedro e Convento , Xocó, 2006. Foto: 


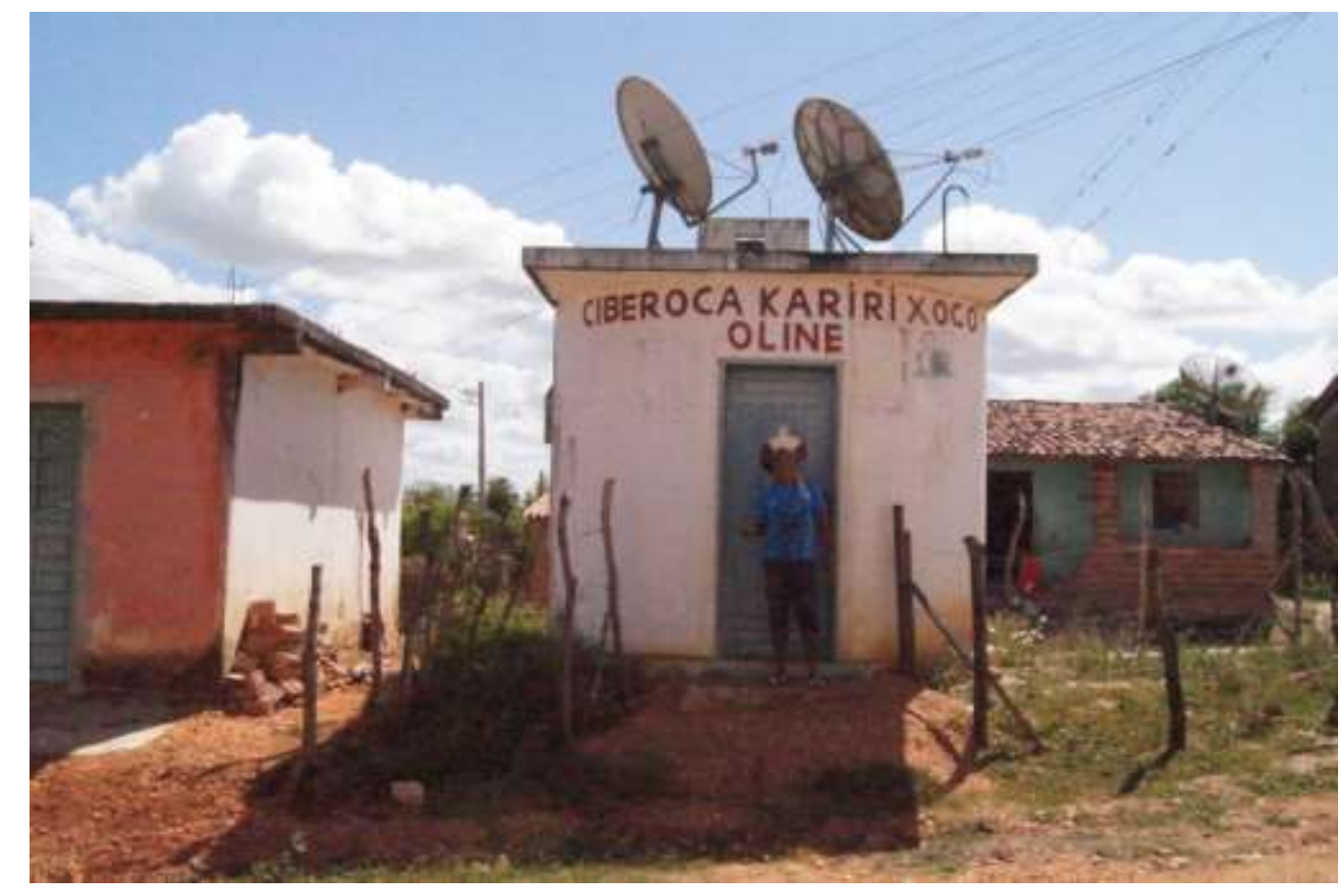

2013. Acervo equipe Atlas/AVAL
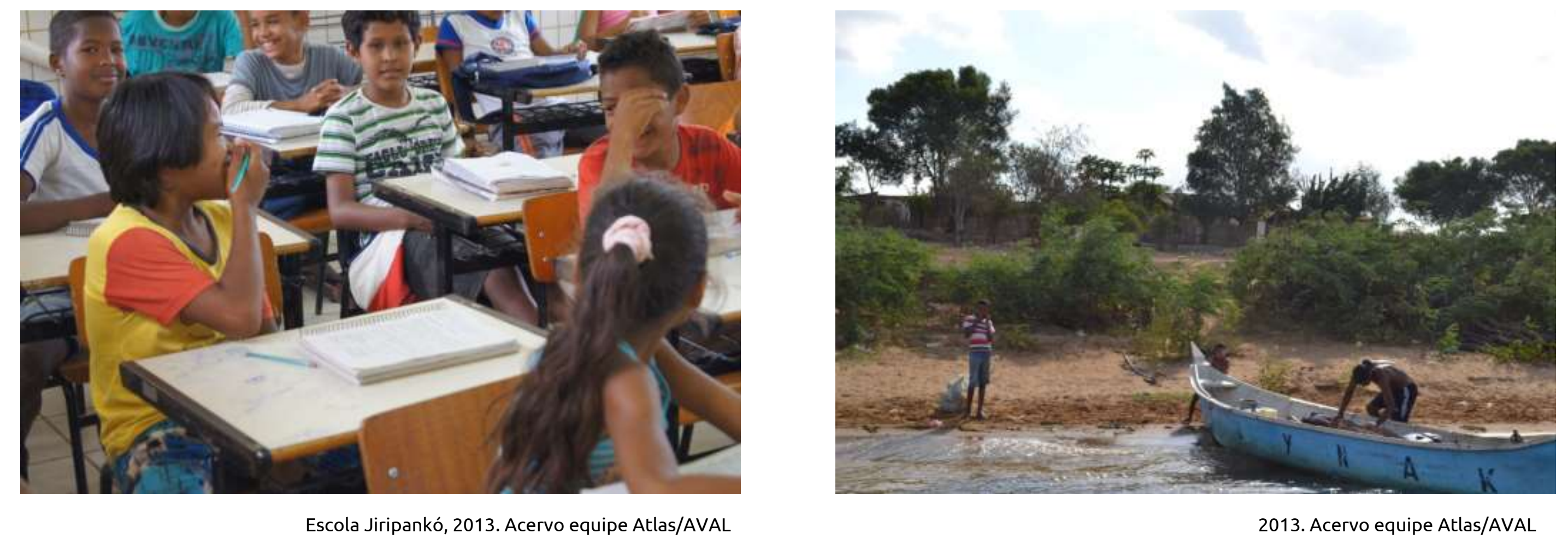

2013. Acervo equipe Atlas/AVAL 


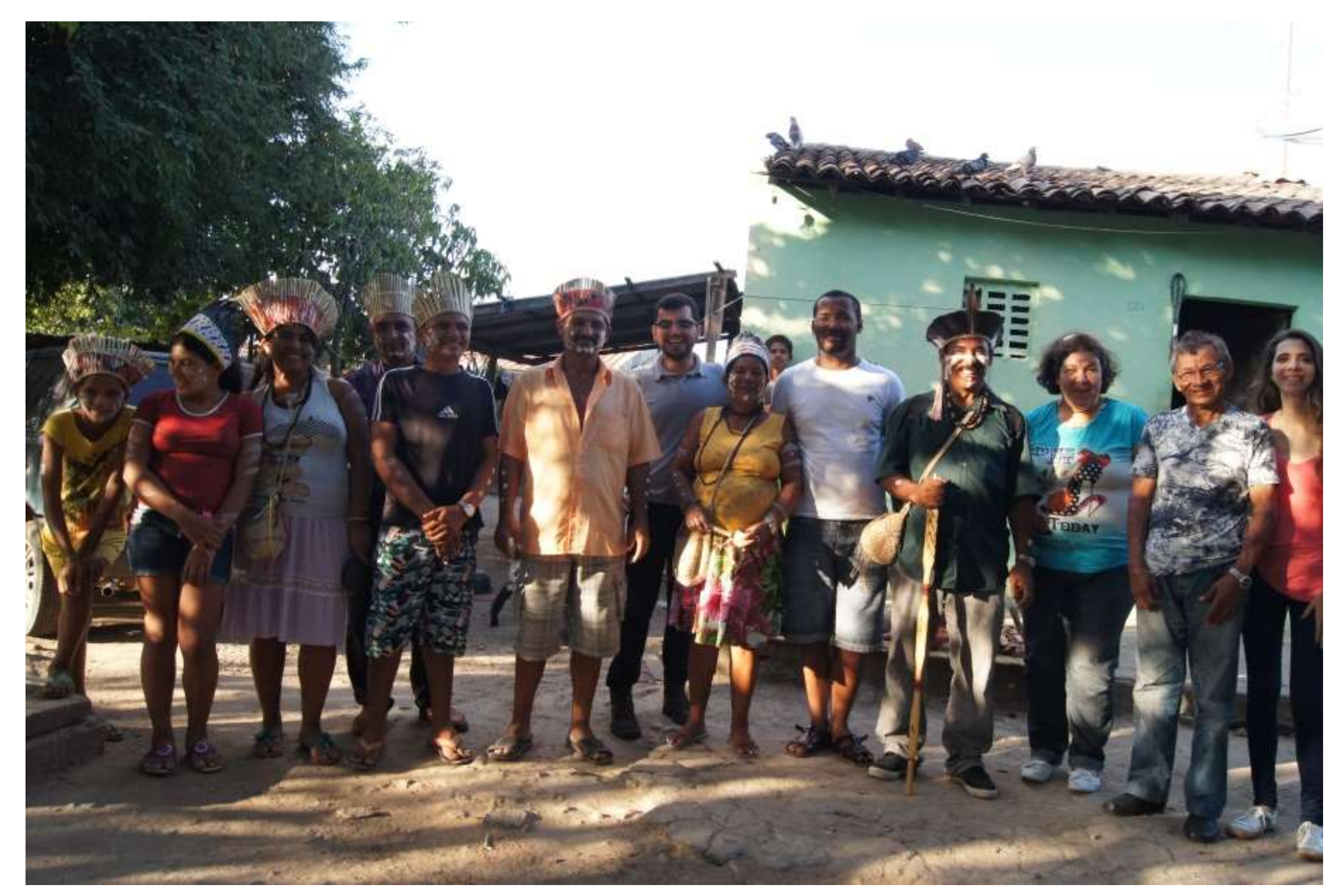


